\title{
$362 \mathrm{kV}$ GIB 내에서 건조공기의 절연파괴 특성
}

\section{한기선 ${ }^{1, a}$, 주형준 ${ }^{1}$, 윤진열 ${ }^{1}$, 유홍근 ${ }^{1}$}

1 한국전력공사 전력연구원 송배전연구소

\section{Breakdown Characteristics of Dry Air under 362 kV GIB}

\author{
Ki-Son Han ${ }^{1, a}$, Hyung-Jun $\mathrm{Ju}^{1}$, and Jin-Yul Yoon ${ }^{1}$, and Hong-Geun You ${ }^{1}$ \\ ${ }^{1}$ Transmission and Distribution Laboratory, Korea Electric Power Research Institute, Daejon 305-380, Korea
}

(Received August 16, 2010; Revised September 14, 2010; Accepted September 17, 2010)

\begin{abstract}
In this paper, we studied the dielectric breakdown voltage characteristics by the AC withstand voltage test on using green insulation dry air instead of $\mathrm{SF}_{6}$ insulation gas used in the GIB (gas insulated bus) of $362 \mathrm{kV}$ GIS (gas insulated switchgear). The AC withstand voltage test applied to the standard KEPCO's $362 \mathrm{kV}$ GIB with dry air insulation, and the equivalence of dielectric breakdown voltage for dry air and $\mathrm{SF}_{6}$ gas were examined, and the empirical formulas of dielectric breakdown voltage for dry air were calculated, and the criterion of $\mathrm{AC}$ withstand voltage test for dry air insulation was derived. Using the criterion, dry air can be used instead of $\mathrm{SF}_{6}$ gas for $362 \mathrm{kV}$ GIB in the factory acceptance test was confirmed.
\end{abstract}

Keywords: 362 kV GIS, 362 kV GIB, Dry air, Breakdown voltage charecteristic, AC withstand voltage

\section{1. 서 론}

초고압 변전기기의 절연매체로써 널리 사용되고 있 는 $\mathrm{SF}_{6}$ 가스는 높은 절연내력과 우수한 아크소호능 력, 무독성 및 안정적인 열적·화학적 특성을 가지고 있고, 공기 절연에 비해 약 $20 \%$ 의 공간으로 설치가 가능하여 변전기기의 축소화 및 고신뢰화를 가능하게 하였다. 그러나 $\mathrm{SF}_{6}$ 가스는 저온 및 고압에서 액화되 기 쉽고 불평등 전계에서 절연내력이 낮아지며 다른 가스에 비해 가격이 비싼 단점이 있다. 특히 $\mathrm{SF}_{6}$ 가 스는 지구온난화지수 (global warming potential, $\mathrm{GWP}$ )가 $\mathrm{CO}_{2}$ 의 23,900배로 매우 높고 화학적으로 안 정되어 있어 지구온난화에 끼치는 영향이 지대하므로 2005년 교토의정서에 의해 온실가스에 포함되었다. 우리나라는 2013년부터 $\mathrm{SF}_{6}$ 가스 감축이 불가피할 것 으로 예상되므로 한전과 중전기기 제작사는 $\mathrm{SF}_{6}$ 가스 를 절감할 수 있는 다양한 연구와 개발이 필요할 것 으로 판단된다. 특히 $\mathrm{SF}_{6}$ 가스는 $100 \%$ 회수가 곤란

a. Corresponding author; hankison@kepco.co.kr
하여 중전기기 제작사의 공장 검수시험 시 약 $30 \%$, 한전의 설비 유지보수 및 증설시 약 $20 \%$ 가 미회수되 어 대기 중으로 배출되고 있어 $\mathrm{SF}_{6}$ 가스 절감대책에 대한 연구가 절실한 실정이다. 따라서 본 논문에서는 공장시험 시 대기 중으로 배출되는 약 $30 \%$ 의 $\mathrm{SF}_{6}$ 가 스 미회수를 막기 위해 대체 방법으로 $\mathrm{N} 2$ 가스와 $\mathrm{O}_{2}$ 가스가 혼합된 건조공기의 적용 가능성을 확인하고자 하였다.

$362 \mathrm{kV}$ GIB (gas insulated bus)의 절연매체로 $\mathrm{SF}_{6}$ 가스와 건조공기 사용 시 전계해석을 통하여 건조공 기의 대체 적용 가능성을 검토하였으며, 한전 현장에서 설치 운영하고 있는 GIS (gas insulated switchgear) 의 약 $67 \%$ 를 점유하고 있는 효성중공업에서 제작한 $362 \mathrm{kV}$ 상분리형 $\mathrm{GIB}$ 와 상일괄형 $\mathrm{GIB}$ 를 대상으로 상용주파전압을 인가하여 건조공기의 압력변화에 따 른 상용주파 절연파괴 실험을 통하여 측정한 절연파 괴전압과 $\mathrm{SF}_{6}$ 가스 사용 시의 절연파괴전압을 비교하 고 등가성을 분석하여 건조공기 사용 시 절연파괴전 압 실험식을 산출하였다. 또한 산출된 절연파괴전압 


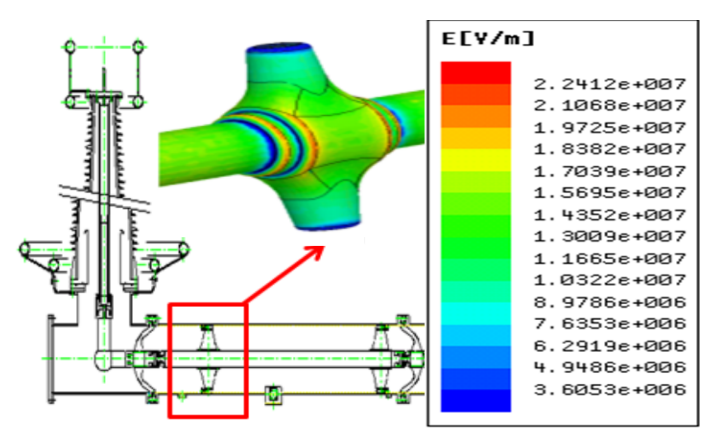

Fig 1. $362 \mathrm{kV} 1$ phase type GIB \& electric field distribution.

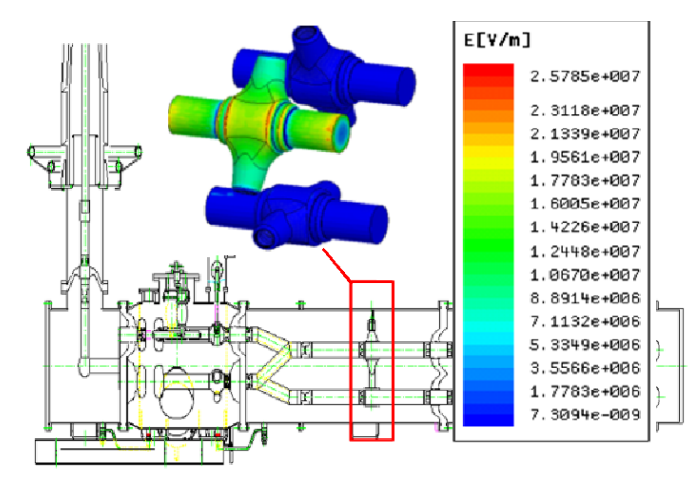

Fig. 2. $362 \mathrm{kV} 3$ phase type GIB \& electric field distribution.

실험식으로부터 상용주파내전압 시험 기준식을 도출 하고 적합도를 검증하기 위하여 전계해석상의 취약한 부위에 이물질을 부착하여 실제 절연파괴가 내전압 시험기준 값 이하에서 발생하는지를 확인하였다. 이 상의 실험결과 본 논문에서는 $\mathrm{SF}_{6}$ 가스 사용량을 감 축하기 위하여 $362 \mathrm{kV}$ GIB의 공장 검수시험 시에 $\mathrm{SF}_{6}$ 가스 대신 대체 절연가스인 건조공기의 적용 가 능성을 제시하고자 한다.

\section{2. 실험 방법}

$362 \mathrm{kV}$ GIB에 절연매체로 $\mathrm{N}_{2}$ 가스와 $\mathrm{O}_{2}$ 가스가 혼합된 건조공기 사용 시 내부 구조물에 분포되는 전 계를 기존의 $\mathrm{SF}_{6}$ 가스 사용 시 전계와 비교하기 위해 전계해석 프로그램인 Ansys사의 Maxwell 3D를 사용 하여 해석하였다. 실제 한전에서 사용중인 효성중공 업제의 $362 \mathrm{kV}$ 상분리형과 상일괄형 $\mathrm{GIB}$ 를 대상으로
Table 1. Electric field strength with $\mathrm{SF}_{6}$ gas insulated and dry air insulated.

\begin{tabular}{ccccccccc}
\hline \multirow{2}{*}{$\begin{array}{c}\text { Pressurdition } \\
\text { [Atm] }\end{array}$} & \multicolumn{2}{c}{$\begin{array}{c}\text { MAximum electric field } \\
{[\mathrm{kV} / \mathrm{mm}]}\end{array}$} & \multicolumn{4}{c}{$\begin{array}{c}\text { Flash over voltage } \\
{[\mathrm{kV}]}\end{array}$} \\
\cline { 2 - 9 } & \begin{tabular}{c} 
Dry air \\
\hline \hline
\end{tabular} & $\begin{array}{c}\mathrm{SF}_{6} \\
\text { gas }\end{array}$ & \multicolumn{2}{c}{ Dry air } & \multicolumn{2}{c}{$\mathrm{SF}_{6}$ gas } \\
\cline { 2 - 9 } & 1 phase 3 phase $\begin{array}{c}\text { standar } \\
\mathrm{d} \text { level }\end{array}$ & $\begin{array}{c}1 \\
\text { phase }\end{array}$ & 3 & phase & $\begin{array}{c}1 \\
\text { phase }\end{array}$ & 3 phase \\
\hline 1 & 2.41 & 2.07 & 3.94 & 151.2 & 113.9 & 248.7 & 217.1 \\
\hline 3 & 5.42 & 5.41 & 8.27 & 341.5 & 297.6 & 521.0 & 454.9 \\
\hline 5 & 6.40 & 6.87 & 11.18 & 403.2 & 377.9 & 704.3 & 614.9 \\
\hline
\end{tabular}

하였으며 건조공기가 $1,3,5$ 기압으로 충진된 경우를 가정하여 절연파괴에 가장 취약한 부위인 포스트부의 전계분포를 해석하였다.

그림 1 에 해석에 사용된 $362 \mathrm{kV}$ 상분리형 $\mathrm{GIB}$ 모 델과 전계해석 분포를 나타냈으며, 그림 2 는 해석에 사용된 $362 \mathrm{kV}$ 상일괄형 $\mathrm{GIB}$ 모델과 전계해석 분포 를 보여준다. 건조공기 절연시 전계해석 결과는 기존 $\mathrm{SF}_{6}$ 가스 절연의 경우와 비교하여 표 1 에 나타내었 다.

표 1 의 전계해석 결과 건조공기 절연시 $362 \mathrm{kV}$ 상 분리형 $\mathrm{GIB}$ 포스트부의 최고전계강도는 $\mathrm{SF}_{6}$ 가스절 연과 비교하여 압력에 따라 평균 $60 \%$ 의 값을 나타냈 으며, 상일괄형 $\mathrm{GIB}$ 포스트부의 최고전계강도는 $\mathrm{SF}_{6}$ 가스절연과 비교하여 압력에 따라 평균 $61 \%$ 의 값을 보였다. 절연파괴전압도 최고전계강도와 같은 결과를 보였다. 따라서 건조공기로 절연한 경우가 $\mathrm{SF}_{6}$ 가스 절연과 비교하여 낮은 전계강도 분포와 절연파괴전압 특성을 보임을 알 수 있었다. 또한 충진된 건조공기 압력에 따라 $362 \mathrm{kV} \mathrm{GIB}$ 상일괄형 포스트부가 상분 리형 포스트부보다 높은 전계강도와 낮은 절연파괴전 압을 보였다.

건조공기 절연 시 최고전계강도를 고려하여 계산으 로 얻어진 절연파괴전압은 그림 3 과 같이 압력이 증 가함에 따라 상분리형과 상일괄형 $\mathrm{GIB}$ 포스트부 모 두 증가하는 경향을 보이며, 이는 $\mathrm{SF}_{6}$ 가스절연과 유 사한 특성을 보인다. 즉 건조공기 절연시 절연파괴전 압은 기존의 $\mathrm{SF}_{6}$ 가스절연과 비교하여 일정한 패턴을 갖고 있음을 확인하였다.

따라서 전계해석 결과 $362 \mathrm{kV}$ GIB에 대한 상용주 파내전압 시험 시 $\mathrm{SF}_{6}$ 가스를 대체하여 건조공기의 사용 가능성을 알 수 있었다. 


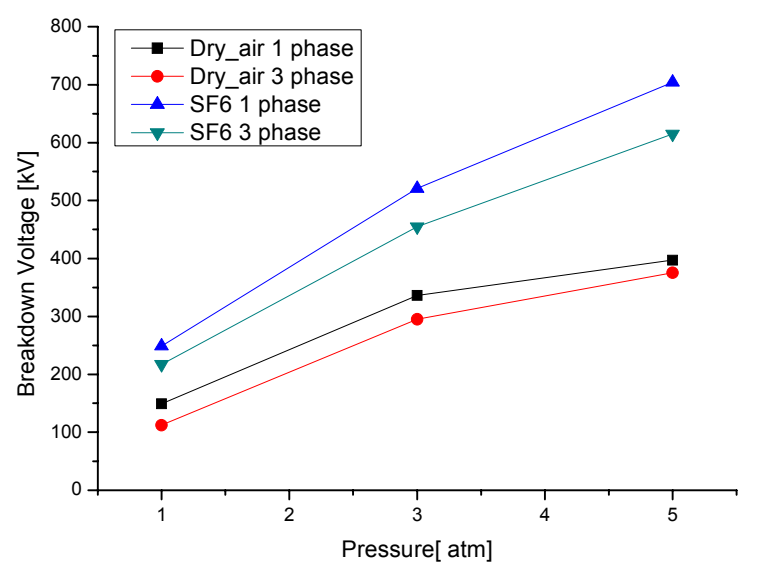

Fig. 3. Breakdown voltage of $\mathrm{SF}_{6}$ gas and dry air insulated.

\section{3. 결과 및 고찰}

\section{1 실험장치}

실험은 한전 현장에서 설치 운영하는 효성중공업제 의 $362 \mathrm{kV}$ 상분리형 $\mathrm{GIB}$ 와 상일괄형 $\mathrm{GIB}$ 를 대상으 로 건조공기와 $\mathrm{SF}_{6}$ 가스를 절연가스로 충진하여 실험 하였다.

실험장치의 구성은 그림 4 와 같으며 $\mathrm{GIB}$ 에 전압을 가하는 내전압 시험기의 출력전압은 최대 $800 \mathrm{kV}$ 이 며 $\mathrm{GIB}$ 에 충진하는 건조공기의 성분은 표 2 에 따른 다.

\section{$3.2 \mathrm{AC}$ 상용주파 절연파괴 실험 및 특성}

$\mathrm{AC}$ 상용주파 절연파괴 실험대상인 $362 \mathrm{kV}$ 상일괄 형과 상분리형 $\mathrm{GIB}$ 는 조립 후 진공작업을 실시하고 $\mathrm{GIB}$ 내부의 진공도를 확인하여 0.03 Torr 이하를 유 지하였다. 건조공기와 $\mathrm{SF}_{6}$ 가스를 1 기압에서 5 기압의 조건으로 충진한 후 수분을 측정하여 $10 \mathrm{ppm}$ 이하를 유지하였다. $\mathrm{AC}$ 내전압 시험기를 통하여 $60 \mathrm{~Hz}$ 의 인 가전압을 $1 \mathrm{kV}$ 씩 증가하며 절연파괴전압을 측정하였 다. 각 실험 후 $\mathrm{GIB}$ 를 분해하여 절연파괴 위치를 확 인하고 보수점검 및 재조립하여 가스를 충진하고 재 실험하였다. $\mathrm{AC}$ 내전압 시험기의 인가전압 상승은 예상파괴전압의 $70 \%$ 까지는 직선상승법을 적용하고, 이후는 $1 \mathrm{kV} / \mathrm{s}$ 의 계단상승법을 적용하여 실험하였다. 건조공기의 압력은 $1,3,5$ 기압을 적용하였으며 비교 실험인 $\mathrm{SF}_{6}$ 가스절연의 경우 순도 $95 \%$ 이상의 가스

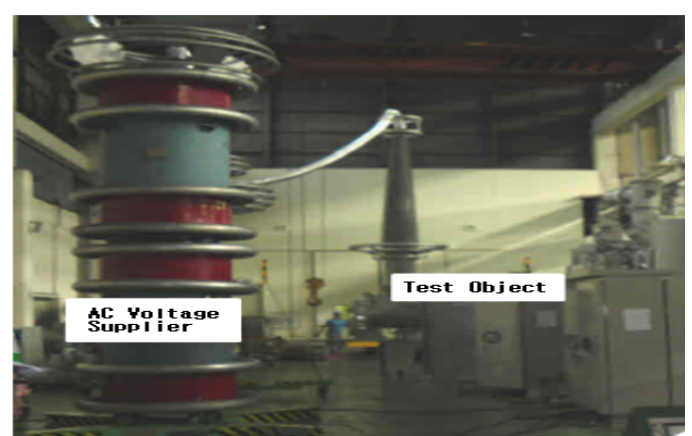

Fig. 4. AC withstand voltage test equipment configuration.

Table 2. Components of dry air used in the experiments.

\begin{tabular}{ccc}
\hline No. & Component & Composition, \\
\hline \hline 1 & $\mathrm{O}_{2}$ & Less than $19.5 \%$ \\
\hline 2 & $\mathrm{~N}_{2}$ & $80 \%$ \\
\hline 3 & Dew point & Less than $-65^{\circ} \mathrm{C}$ \\
\hline 4 & Moisture contain & Less than $10 \mathrm{ppm}$ \\
\hline
\end{tabular}

Table 3. AC breakdown voltage experimental results of dry air.

\begin{tabular}{|c|c|c|c|c|}
\hline \multirow[b]{2}{*}{ Pressure } & \multicolumn{2}{|c|}{$\begin{array}{c}\text { Breakdown voltage by } \\
\text { experiment }[\mathrm{kV}]^{*)}\end{array}$} & \multicolumn{2}{|c|}{$\begin{array}{c}\text { Breakdown voltage by } \\
\text { simulation }[\mathrm{kV}]\end{array}$} \\
\hline & 1 phase & 3 phase & 1 phase & 3 phase \\
\hline 1 & 149.05 & 112.28 & 151.2 & 113.9 \\
\hline 3 & 336.26 & 295.31 & 341.5 & 297.6 \\
\hline 5 & 397.16 & 375.49 & 403.2 & 377.9 \\
\hline
\end{tabular}

*) $95 \%$ confidence interval minimum value

를 1 기압으로 충진하여 실험하였고 절연파괴특성 실 험에서 전압인가 횟수는 매 조건에서 30회 이상으로 하였다. 건조공기 사용 시 $\mathrm{AC}$ 상용주파 절연파괴 실 험결과는 표 3 과 같이 나타내었다.

실험을 통하여 절연파괴 실험식을 구하는 방법은 다양한 방법이 보고되고 있으나, 본 연구에서는 실험 데이터의 신뢰도 구간 $95 \%$ 를 적용하여 최소 절연파 괴전압을 사용하여 Allometry방법으로 실험식을 도출 하였다. 도출된 $362 \mathrm{kV}$ 상분리형 $\mathrm{GIB}$ 와 상일괄형 $\mathrm{GIB}$ 의 $\mathrm{AC}$ 상용주파 절연파괴 실험식은 다음의 식 (1), (2)와 같다.

$$
\begin{aligned}
& V_{b d}=153.481 P^{0.62989} 362 \mathrm{kV} \text { 상분리형 } \mathrm{GIB} \\
& V_{b d}=115.5794 P^{0.7708} 362 \mathrm{kV} \text { 상일괄형 } \mathrm{GIB}
\end{aligned}
$$




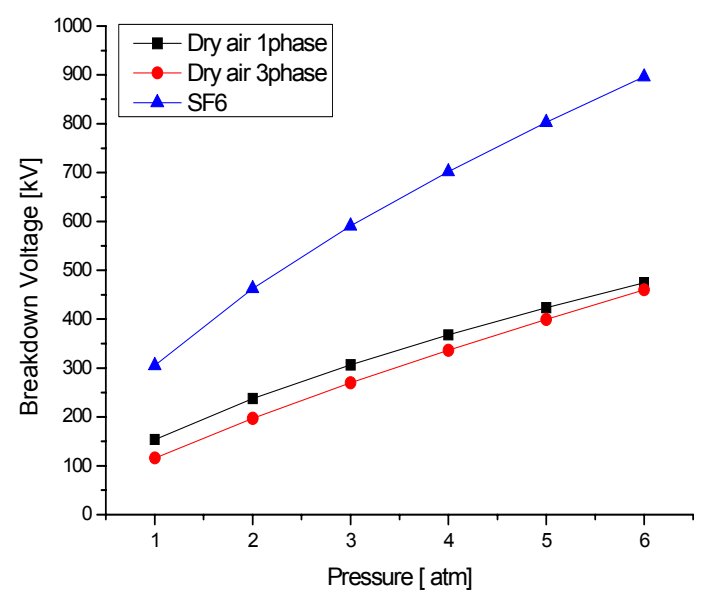

Fig. 5. The breakdown voltage of dry air and $\mathrm{SF}_{6}$ gas.

건조공기 절연인 경우의 상기 $\mathrm{AC}$ 상용주파 절연파 괴 실험식과 $\mathrm{SF}_{6}$ 가스 사용 시 전계해석에 의해 각각 계산된 절연파괴전압을 압력에 따라 그림 5 와 같이 비교하여 등가성을 확인하였으며, 표 3에서 실제 실 험에 의한 절연파괴전압과 전계해석에 의한 절연파괴 전압을 비교하여 실험데이터의 정합성을 검증하였다. 이상의 실험결과 $362 \mathrm{kV} \mathrm{GIB}$ 에 대한 상용주파내전압 시험 시 $\mathrm{SF}_{6}$ 가스를 대체하여 건조공기의 사용이 가 능한 것으로 판단된다.

건조공기를 사용하여 $362 \mathrm{kV}$ GIB의 상용주파내전 압 시험 시 적용하기 위한 기준식을 도출하기 위해서 는 상기 도출된 $\mathrm{AC}$ 상용주파 절연파괴 실험식 중 절 연파괴전압이 낮은 $362 \mathrm{kV}$ 상일괄형 $\mathrm{GIB}$ 에 대한 실 험식을 적용하는 것이 바람직한 것으로 판단된다. 따 라서 $362 \mathrm{kV}$ 상일괄형 $\mathrm{GIB}$ 의 상용주파 절연파괴 실 험식에 실험데이터의 확률편차 $\sigma$ (0.984)와 효성중공 업에서 상용주파내전압 계산시 적용하는 오차계수 $\mathrm{K}_{1}$ (0.9)과 오손계수 $\mathrm{K}_{2}$ (0.95)를 적용하여 상용주파 내전 압 기준식을 다음과 같이 도출하였다.

$$
V_{s}=115.58 P^{0.7708} \cdot \sigma \cdot K_{1} \cdot K_{2}
$$

\section{3 결함에 의한 상용주파내전압 기준식 검증}

도출된 $362 \mathrm{kV}$ GIB의 상용주파 내전압 기준식을 검증하기 위해 인위적으로 길이 $1 \mathrm{~cm}$, 두께 $1 \mathrm{~mm}$ 인 금속 이물질을 그림 6 과 같이 $362 \mathrm{kV}$ 상일괄형과 상 분리형 GIB 내에 부착한 후 절연파괴 실험을 시행하 였다. 이물질의 부착위치는 전계해석결과 최고의 전
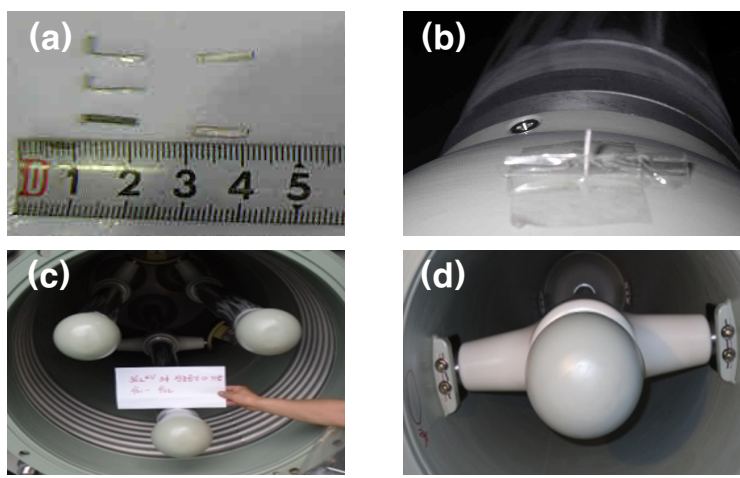

Fig. 6. Photos of metallic defect, and attached inside GIB. (a) Defects (b) Defect on 1 phase GIB (c) Defect on 3 phase end part of GIB (d) Defect on 1 phase end part of GIB

Table 4. AC breakdown voltage experimental results by metal defects.

\begin{tabular}{ccc}
\hline Division & $\begin{array}{c}\text { AC breakdown } \\
\text { voltage } \\
{[\mathrm{kV}]}\end{array}$ & $\begin{array}{c}\text { AC experimental } \\
\text { breakdown voltage } \\
\text { by equation } \\
{[\mathrm{kV}]}\end{array}$ \\
\hline \hline 1 Phase type & $\frac{185}{190}$ \\
\hline \multirow{3}{*}{3 phase type } & \multirow{2}{*}{226} \\
\cline { 2 - 3 } & $\frac{175}{176}$ \\
\hline
\end{tabular}

계분포를 갖는 스페이서, 포스트 및 말단부에 부착하 였다. GIB 내부의 건조공기 압력은 3기압의 조건으로 유지한 후 수분은 $10 \mathrm{ppm}$ 이하를 유지하였다. 표 4에 금속 이물질에 의한 $\mathrm{AC}$ 상용주파 절연파괴 실험결과 를 나타내었으며 상용주파 내전압 기준식에 의해 산 출한 전압 $(226 \mathrm{kV})$ 보다 낮은 전압에서 절연파괴가 발생함을 확인함으로써 상용주파 내전압 기준식의 적 용 가능성을 검증하였다.

\section{4. 결 론}

본 논문에서는 실제 한전에서 사용하는 $362 \mathrm{kV}$ $\mathrm{GIB}$ 에서 기존 $\mathrm{SF}_{6}$ 가스 대신 건조공기를 사용하여 상용주파전압에 의한 절연파괴 특성을 연구하였다. 상용주파전압을 인가하여 건조공기와 $\mathrm{SF}_{6}$ 가스의 절 연파괴전압을 비교하여 등가성을 확인하고 건조공기 에 대해서 상용주파 절연파괴 실험에 의한 전압과 전 
계해석에 의한 절연파괴전압을 비교하여 실험 데이터 의 정합성을 검증하여 건조공기에 대한 상용주파 절 연파괴 실험식을 산출하였다. 이 실험식에 확률편차, 오차계수 및 오손계수를 적용하여 $362 \mathrm{kV} \mathrm{GIB}$ 에 대 해 상용주파내전압 시험 시 기준식을 도출하였으며, 이물질에 의한 절연파괴 실험을 통해 상용주파 내전 압 기준식에 대해 검증하였다. 따라서 본 연구를 통 해 도출한 $362 \mathrm{kV}$ GIB에 대한 상용주파내전압 기준 식을 이용하여 $\mathrm{SF}_{6}$ 가스를 대체하여 건조공기를 사용 한 상용주파내전압 시험 가능성을 제시함으로써 한전 및 중전기기 제작사의 공장 검수시험 시 $\mathrm{SF}_{6}$ 가스가 대폭 절감될 것으로 기대되어 진다.

\section{REFERENCE}

[1] J.-D. Kim, W.-P. Song, and D.-E. Kim, Proceeding of KIIEE, 7, 21 (1993).

[2] N. H. Melik and A. H. Qureshi, IEEE Trans. Electr.
Insul. EI-14, 1 (1979).

[3] E.-H. Cho, B.-H. Goo, E.-K. Kim, and K.-S. Lee, Trans. KIEE 23, 5 (2009).

[4] M. Landry, G. St-Jean, R. Jeanjean, and D. Demissy, IEEE Trans. Power Deliv. 3, 1029, 1988.

[5] M. Hikita, T. Hoshino, T. Kato, N. Hayakawa, T. Ueda, and H. Okubo, IEEE Int. Symp. Electr. Insul. (IEEE, Montreal, Canada, 1996) pp. 117.

[6] C. Beyer, H. Jenett, and D. Klockow, IEEE Trans. Dielectr. Electr. Insul. 7. 234 (2000).

[7] K.-S. Lee, Trans. KIEE, 52C, 8 (2003).

[8] N. Hayakawa, K. Hatta, S. Okabe, and H. Okubo, IEEE Trans. Dielectr. Electr. Insul. 13, 842 (2006).

[9] E.-H. Choi, K.-S. Park, J.-W. Kim, C.-H. Lim, and K.-S. Lee, 8th International Conference on Properties and applications of Dielectric Materials ICPADM 2006, (IEEE, Bali, Indonesia, 2006) p. 396.

[10] C. - H. Lee, Y.-S. Kim, J.-B. Kim, Y.-G. Choi, and K.-S. Lee, equal/unequal electric field breakdown characteristics of Dry air insulation, Conf. KIIEE (KIIEE, Korea, 2007) p. 247. 